\title{
Uso de manipueira no desenvolvimento vegetativo do milho em ambiente protegido ${ }^{1}$
}

\author{
Fernanda Z. Saraiva ${ }^{2}$, Silvio C. Sampaio ${ }^{2}$, Marciane G. Silvestre², Manoel M. F. de Queiroz ${ }^{2}$, Lúcia H. P. Nóbrega ${ }^{2}$ \& Benedito M. Gomes ${ }^{2}$
}

\section{RESUMO}

Avaliaram-se efeitos da água residuária de fecularia tratada por sistema de lagoas, na cultura do milho. A irrigação com água residuária propiciou aumento de todos os parâmetros químicos do solo, proporcional aos respectivos tratamentos como segue: L1E (efluente da lagoa de decantação), L1ED (efluente da lagoa de decantação diluído em 50\%), L2E (efluente da primeira lagoa anaeróbia), L2ED (efluente da primeira lagoa anaeróbia diluído em 50\%), L3E (efluente da segunda lagoa anaeróbia), L3ED (efluente da segunda lagoa anaeróbia diluído em 50\%) e T (testemunha sem adubação, irrigação com água) exceto para o tratamento TA (testemunha com adubação $85 \mathrm{~kg} \mathrm{ha}^{-1} \mathrm{~K}_{2} \mathrm{O} ; 60 \mathrm{~kg} \mathrm{ha}^{-1} \mathrm{~N} ; 100 \mathrm{~kg} \mathrm{ha}^{-1} \mathrm{P}_{2} \mathrm{O}_{5} \mathrm{e}$ irrigação com água) que também mostrou altos teores dos elementos avaliados; maiores alturas de planta foram obtidas nos tratamentos L1E, TA, T, os quais diferiram entre si, seguidos de L1ED, L2ED e L3ED, semelhantes estatisticamente, e de L2E e L3E também foram iguais entre si, a $5 \%$ de probabilidade; o número de folhas não diferiu significativamente entre tratamentos mas apenas teores de fósforo e zinco mostraram diferenças significativas entre tratamentos nas análises químicas do tecido foliar e das raízes.

Palavras-chave: água residuária, fecularia, reúso, Zea mays L.

\section{Use of cassava industry wastewater in the vegetative development of corn in a protected environment}

\begin{abstract}
This study evaluated the effects of the wastewater of cassava industry, treated by pond system, on the corn crop. The irrigation with wastewater resulted in an increase in chemical parameters of the soil, proportional to the respective treatments in the following order: L1E (effluent of the decantation pond), L1ED (effluent of the pond of decantation with $50 \%$ dilution), L2E (effluent of the first anaerobic pond), L2ED (effluent of the first anaerobic pond with $50 \%$ dilution), L3E (effluent of the second anaerobic pond), L3ED (effluent of the second anaerobic pond with $50 \%$ dilution) and T (control without fertilization and irrigation with water) except for the treatment TA (control with fertilization: $85 \mathrm{~kg} \mathrm{ha}^{-1}$ $\mathrm{K}_{2} \mathrm{O} ; 60 \mathrm{~kg} \mathrm{ha}^{-1} \mathrm{~N} ; 100 \mathrm{~kg} \mathrm{ha}^{-1} \mathrm{P}_{2} \mathrm{O}_{5}$ and irrigation with water:); the height of plant for the treatments varied in the following order: L1E, TA, T which differed significantly followed by L1ED, L2ED and L3ED statistically similar; and L2E and L3E which also showed similar results without significant differences at $5 \%$ probability level. The number of leaves did not present significant differences among the evaluated treatments, only the concentrations of phosphorus and zinc in the leaves and roots presented significant differences.
\end{abstract}

Key words: wastewater, cassava industries, reuse, Zea mays L.

1 Parte da Dissertação de Mestrado da primeira autora, apresentada a Universidade Estadual do Oeste do Paraná - UNIOESTE

${ }^{2}$ RHESA/UNIOESTE, Rua Universitária, 2069, CEP 85819-110, Cascavel, PR. Fone: (45) 3220-3262. E-mail: fernanda@fag.edu.br; ssampaio@unioeste.br; marci.sil@ibest.com.br; mfqueiroz@unioeste.br; Ihpn@unioeste.br; bmgomes@unioeste.br 


\section{INTRODUÇÃO}

A quantidade de mandioca produzida no Paraná propicia, ao Estado, o $2^{\circ}$ lugar no ranking nacional, superado apenas pelo estado do Pará. Esta produção corresponde a 3,9 milhões de toneladas, ou seja, 17\% da produção brasileira (SEAB/DERAL, 2003).

A cultura da mandioca é matéria-prima para muitos produtos de uso geral, como alimentos diversos, produtos de higiene, tintas e colas, entre outros. Porém, como em qualquer atividade produtiva, também gera resíduos culturais e subprodutos derivados de processos industriais, como a manipueira (Tiese-Nhausen, 1987; Pereira, 1987).

A manipueira é um líquido de aspecto leitoso, de cor amarelo-claro oriunda das raízes da mandioca, por ocasião da prensagem da mesma, com vistas à obtenção da fécula ou farinha de mandioca que, fisicamente, se apresenta na forma de suspensão aquosa e, quimicamente, como miscelânea de compostos, como goma, açúcares, proteínas, linamarina, derivados cianogênicos, substâncias e sais minerais diversos. Esta característica da manipueira consiste em sério problema ambiental quando lançada diretamente em corpos hídricos, principalmente se considerados os pequenos cursos d'água, onde comumente acontecem os despejos dos resíduos líquidos de indústrias que utilizam raízes de mandioca como matéria-prima (Cereda, 2001).

Mengel \& Kirkly (1987) salientaram que a disposição de manipueira no solo provoca danos imediatos à cultura instalada porém, após certo tempo, a área se cobre de plantas que apresentam novo vigor, fato que gerou a expectativa de se avaliar conseqüências agronômicas da fertilidade com este resíduo, objetivando-se a avaliação do solo e planta e também demonstrou a necessidade de tratamento adequado para posterior reúso.

Segundo Silva (2003), a composição química da manipueira sustenta também a potencialidade do composto como adubo, haja vista sua riqueza em nitrogênio, fósforo e, principalmente, em potássio. Por outro lado, a presença de cianetos explica os efeitos nematicida e inseticida inerentes à manipueira. Estudos de Vieites \& Brinholi (1994) corroboram com o autor anterior quando observaram respostas positivas na utilização da manipueira, nas doses de 60 e $120 \mathrm{~m}^{3}$ ha $^{-1}$ associadas à adubação mineral, na cultura da mandioca, com aumento do comprimento e diâmetro das raízes e elevação da produtividade. Ao contrário de Fioretto (1994), estudando o efeito de cinco doses $(0,80,120$, 160 e $200 \mathrm{~m}^{3} \mathrm{ha}^{-1}$ ) na mesma cultura, verificou que todos os tratamentos que receberam manipueira produziram menos que a testemunha.

Visando realizar um estudo que permitisse avaliar esse potencial fertilizante da manipueira utilizando o vegetal mais produzido no Paraná, que propicia ao estado responder por $27 \%$ do total da produção nacional, segundo SEAB/DERAL (2003), justifica-se o objetivo deste trabalho, que é avaliar o efeito da aplicação de manipueira no desenvolvimento vegetativo do milho, em ambiente protegido.

\section{MATERIAL E MÉTODOS}

O experimento foi instalado em área da Fundação para o Desenvolvimento Científico e Tecnológico - FUNDETEC, localizada na BR 277, km 573, no município de Cascavel, Estado do Paraná, em latitude $25^{\circ} 10^{\prime}$ Sul, longitude $53^{\circ} 20^{\prime}$ Oeste e altitude de $750 \mathrm{~m}$. O clima é subtropical, com temperatura média anual de $19^{\circ} \mathrm{C}$ e umidade relativa do ar média anual de $70 \%$.

$\mathrm{Na}$ área escolhida para realização do experimento, foi construída uma casa de vegetação em polietileno, no sentido Norte-Sul, com dimensões de 3,0 x 7,0 m, totalizando $21 \mathrm{~m}^{2}$ para melhor adequação e controle do experimento.

Fez-se a semeadura do milho em vasos plásticos com diâmetro de 24 e $23 \mathrm{~cm}$ de altura, com perfurações no fundo para escorrer o excesso da água de irrigação. A distribuição dos vasos foi aleatória, com distância de 50 x 50 cm, os quais foram colocados sob base de tijolos, totalizando 32 vasos.

Efetuou-se a semeadura no dia 20 de janeiro de 2003, período no qual é recomendada a implantação da safrinha de milho na região, utilizando-se sementes de milho híbrido Agroceres 4090. Em cada vaso, semearam-se duas sementes previamente tratadas com inseticidas e fungicidas, determinadas a partir do teste de germinação. Após 15 dias da semeadura foi realizado o desbaste das plantas, deixando-se uma planta por vaso. O ciclo vegetativo avaliado correspondeu a 80 dias em virtude do tamanho do vaso influenciar no crescimento da cultura, seguindo sugestões de Nunes et al. (1992).

Utilizou-se solo com fertilidade alta, classificado como Latossolo Vermelho Distroférrico típico, oriundo de área da COOPAVEL - Cooperativa Agrícola de Cascavel, PR, o qual não necessitou de calagem, visto que já se encontrava com saturação de bases adequada.

A água residuária usada para fertirrigação proveio de uma indústria de fécula de mandioca, localizada no município de Toledo, PR. A indústria dispõe a água residuária gerada pelo processo de obtenção da fécula da mandioca em sistema de lagoas de estabilização, constituído por nove lagoas. Foram usados, no experimento, apenas efluentes das três primeiras lagoas, as quais correspondem à lagoa de decantação e às duas lagoas anaeróbias, respectivamente. Durante a realização do experimento os efluentes das lagoas foram coletados quinzenalmente, totalizando cinco coletas e armazenados sob congelamento. Antes do uso, os respectivos efluentes foram mantidos sobre bancada, até atingirem temperatura ambiente próxima de $20^{\circ} \mathrm{C}$; após, analisaram-se todas as amostras de efluente coletadas, quanto aos parâmetros citados na Tabela 1, seguindo-se a metodologia proposta por APHA (1998).

Os tratamentos definidos a partir dos efluentes usados são descritos a seguir:

L1E: efluente da lagoa de decantação

L1ED: efluente da lagoa de decantação diluído com água destilada em $50 \%$

L2E: efluente da primeira lagoa anaeróbia

L2ED: efluente da primeira lagoa anaeróbia diluído com água destilada em $50 \%$

L3E: efluente da segunda lagoa anaeróbia 
Tabela 1. Teores médios obtidos em cinco coletas dos principais parâmetros físicos e químicos dos efluentes das lagoas 1 (decantação), 2 (anaeróbia) e 3 (anaeróbia), e quantidades de nutrientes aplicados por tratamento (t ha-1)

\begin{tabular}{|c|c|c|c|c|c|c|c|c|c|}
\hline \multicolumn{4}{|c|}{ Análises físico-químicas dos ef́luentes das lagoas } & \multicolumn{6}{|c|}{ Quantidades de nutrientes aplicados por tratamento } \\
\hline Parâmetros & $\begin{array}{l}\text { Lagoa } 1 \\
\left(\mathrm{mg} \mathrm{L}^{-1}\right)\end{array}$ & $\begin{array}{l}\text { Lagoa } 2 \\
\text { (mg L-1) }\end{array}$ & $\begin{array}{l}\text { Lagoa } 3 \\
\left(\mathrm{mg} \mathrm{L}^{-1}\right)\end{array}$ & $\begin{array}{l}\text { L1E } \\
\left(t \mathrm{~h} \mathrm{~h}^{-1}\right)\end{array}$ & $\begin{array}{l}\text { L1ED } \\
\left(\mathrm{t} \mathrm{ha}^{-1}\right)\end{array}$ & $\begin{array}{l}\text { L2E } \\
\left(t \mathrm{ha}^{-1}\right)\end{array}$ & $\begin{array}{l}\text { L2ED } \\
\left(\mathrm{t} \mathrm{ha}^{-1}\right)\end{array}$ & $\begin{array}{l}\text { L3E } \\
\left(t \mathrm{ha}^{-1}\right)\end{array}$ & $\begin{array}{l}\text { L3ED } \\
\left(\mathrm{t} \mathrm{ha}^{-1}\right)\end{array}$ \\
\hline Fósforo & 17,98 & 7,18 & 10,97 & 11,36 & 5,68 & 4,54 & 2,27 & 6,93 & 3,47 \\
\hline Potássio & 227,30 & 102,52 & 90,12 & 143,65 & 71,83 & 64,79 & 32,40 & 56,96 & 28,48 \\
\hline Nitrogênio & 17,60 & 11,60 & 18,4 & 11,12 & 5,56 & 7,33 & 3,67 & 11,63 & 5,81 \\
\hline Cálcio & 42,51 & 44,20 & 18,08 & 26,87 & 13,43 & 27,93 & 13,97 & 11,43 & 5,71 \\
\hline Magnésio & 55,37 & 35,60 & 31,30 & 34,99 & 17,50 & 22,50 & 11,25 & 19,78 & 9,89 \\
\hline Enxofre & 16,42 & 13,89 & 2,18 & 10,38 & 5,19 & 8,78 & 4,39 & 1,38 & 0,69 \\
\hline Boro & 0,50 & 14,58 & 0,24 & 0,32 & 0,16 & 9,21 & 4,61 & 0,15 & 0,08 \\
\hline Cobre & 0,39 & 0,22 & 0,20 & 0,25 & 0,12 & 0,14 & 0,07 & 0,13 & 0,06 \\
\hline Zinco & 0,37 & 0,27 & 0,17 & 0,23 & 0,12 & 0,17 & 0,09 & 0,11 & 0,05 \\
\hline Manganês & 4,80 & 3,61 & 2,19 & 3,03 & 1,52 & 2,28 & 1,14 & 1,38 & 0,69 \\
\hline Ferro & 47,24 & 45,06 & 25,60 & 29,86 & 14,93 & 28,48 & 14,24 & 16,18 & 8,09 \\
\hline Totais & 5.860 & 3.351 & 2.528 & - & - & - & - & - & - \\
\hline Suspensos & 2.216 & 596,60 & 336,80 & - & - & - & - & - & - \\
\hline Fixos & 1.786 & 2.438 & 1.747 & - & - & - & - & - & - \\
\hline Voláteis & 1.786 & 913 & 779 & - & - & - & - & - & - \\
\hline Dissolvidos & 3.558 & 2.755 & 2.187 & - & - & - & - & - & - \\
\hline $\mathrm{pH}$ & 4,85 & 6,34 & 6,82 & - & - & - & - & - & - \\
\hline DQO & 5.850 & 1.313 & 562 & - & - & - & - & - & - \\
\hline
\end{tabular}

L3ED: efluente da segunda lagoa anaeróbia diluído com água destilada em 50\%

T: testemunha sem adubação, irrigação com água

TA: testemunha com adubação (85 kg ha-1 $\mathrm{K}_{2} \mathrm{O}$; $60 \mathrm{~kg} \mathrm{ha}^{-1} \mathrm{~N}$; $100 \mathrm{~kg} \mathrm{ha}^{-1} \mathrm{P}_{2} \mathrm{O}_{5}$ ) irrigação com água

Os respectivos efluentes das lagoas, como descritos nos tratamentos, foram aplicados uma vez por semana em uma taxa de $250 \mathrm{~mL}$ por vaso, correspondendo a uma lâmina de $0,79 \mathrm{~mm} \mathrm{~d}^{-1}$ e um total de $632 \mathrm{~m}^{3} \mathrm{ha}^{-1}$ no ciclo vegetativo avaliado (80 dias). A partir desta dose e dos níveis de concentrações dos parâmetros dos efluentes das lagoas, estimouse a quantidade de nutrientes aplicada no ciclo (Tabela 1).

Irrigações com água foram realizadas proporcionando lâminas médias diárias de $0,79 \mathrm{~mm} \mathrm{~d}^{-1}$ nos primeiros 45 dias, e de 7,01 $\mathrm{mm} \mathrm{d}^{-1}$ nos demais 35 dias, proporcionando lâmina total no ciclo avaliado de $284 \mathrm{~mm}$, conforme recomendado por Dourado Neto \& Francelli (2000).

Ressalta-se que as quantidades de nutrientes aplicadas (Tabela 1) foram maiores que as recomendações consideradas normais em campo, pois neste experimento o cultivo foi feito em ambiente protegido e em vasos que propiciaram altas taxas de drenagem, além dos mesmos não se encontrarem totalmente na forma disponível às plantas.

Semanalmente e antes da aplicação do efluente, as plantas foram medidas quanto à altura, diâmetro de colmo e número de folhas. Para o parâmetro da altura obteve-se, como medida padrão, desde a superfície do solo até o pendão floral. Para o diâmetro foram fixados cinco centímetros da superfície do solo e posterior leitura, com auxílio de um paquímetro digital. É importante citar que o número de folhas por planta, neste experimento, foi contado semanalmente.

Após 80 dias, os solos, as partes aéreas e raízes da cultura, foram coletados e avaliados. As plantas e raízes foram secadas a $65^{\circ} \mathrm{C}$ em estufa, moídas e realizadas análises de micro e macronutrientes e, para o solo, análises de micro e macronutrientes, $\mathrm{pH}$ e condutividade elétrica, segundo metodologia da EMBRAPA (1997).

Os parâmetros químicos do solo foram analisados antes do experimento para se avaliar os efeitos dos tratamentos sobre eles, porém testes estatísticos não foram realizados em virtude de não terem sido realizadas repetições em razão dos custos das análises e não ser objetivo do trabalho. As análises de solo para determinação dos teores de nutrientes e $\mathrm{pH}$ do solo foram realizadas no Laboratório Central de Análises Ltda. - Solanálise, Cascavel, PR. As análises de condutividade elétrica foram realizadas na Universidade Estadual do Oeste do Paraná - UNIOESTE, e ambas seguiram metodologias propostas pela EMBRAPA (1999).

O delineamento experimental utilizado foi inteiramente casualizado com quatro repetições para todos os tratamentos. Os resultados foram interpretados estatisticamente através das análises de variância, em que os efeitos dos tratamentos foram comparados pelo teste "F", adotando-se o nível de $5 \%$ de probabilidade, enquanto as médias das variáveis analisadas foram comparadas pelo teste de Tukey, também ao nível de 5\% de probabilidade.

\section{RESULTADOS E DISCUSSÃO}

\section{Característica do solo após experimento}

Os resultados das análises de solo realizadas em amostras homogeneizadas das parcelas referentes às repetições para cada um dos tratamentos são apresentados na Tabela 2 e foram comparados com os da análise inicial desta mesma área.

Os teores de condutividade elétrica apresentam decréscimo à medida que os tratamentos passaram da lagoa 1 para a 2 e a 3 , com suas respectivas diluições. 
Tabela 2. Análises do solo* coletado após o término do experimento com cultura de milho submetida a tratamentos (Trat) de fertirrigação com água residuária de fecularia (manipueira)

\begin{tabular}{|c|c|c|c|c|c|c|c|c|c|c|c|}
\hline Trat & $\mathrm{pH}$ & $\begin{array}{c}\text { CE } \\
\text { dS } \mathbf{m}^{-1}\end{array}$ & $\begin{array}{c}P \\
\mathrm{mg} \mathrm{dm} \mathbf{~ d m}^{-3}\end{array}$ & $\begin{array}{c}\mathrm{K} \\
\mathrm{mg} \mathrm{dm^{-3 }}\end{array}$ & $\underset{g \mathrm{dm}^{-3}}{C}$ & $\underset{\mathrm{g} \mathrm{dm}}{\mathrm{MO}}$ & $\begin{array}{c}\mathrm{Ca} \\
\mathrm{cmol}_{\mathrm{C}} \mathrm{dm}^{-3}\end{array}$ & $\begin{array}{c}\mathrm{Mg} \\
\mathrm{cmol}_{\mathrm{C}} \mathrm{dm}^{-3}\end{array}$ & $\begin{array}{c}\mathrm{H}+\mathrm{Al} \\
\mathrm{cmol}_{\mathrm{C}} \mathrm{dm}^{-3}\end{array}$ & $\begin{array}{c}\text { CTC } \\
\mathrm{cmol}_{\mathrm{C}} \mathrm{dm}^{-3}\end{array}$ & $\begin{array}{l}\mathbf{V} \\
\%\end{array}$ \\
\hline \multicolumn{12}{|c|}{ Antes do experimento } \\
\hline & 5,4 & 0,300 & 152,20 & 249,6 & 44,050 & 63,120 & 10,59 & 4,82 & 4,61 & 20,66 & 77,6 \\
\hline \multicolumn{12}{|c|}{ Depois do experimento } \\
\hline L1E & 5,8 & 0,668 & 180,5 & 351,0 & 40,500 & 69,700 & 9,0 & 4,1 & 4,0 & 18,7 & 78,9 \\
\hline L1ED & 5,9 & 0,654 & 157,1 & 312,0 & 39,700 & 68,400 & 8,7 & 3,9 & 3,7 & 17,6 & 78,8 \\
\hline L2E & 5,7 & 0,634 & 104,4 & 312,0 & 37,400 & 64,300 & 8,5 & 3,7 & 4,0 & 17,8 & 77,7 \\
\hline L2ED & 6,0 & 0,623 & 95,5 & 234,0 & 36,600 & 63,000 & 8,2 & 3,8 & 3,7 & 17,5 & 77,6 \\
\hline L3E & 5,9 & 0,374 & 76,4 & 312,0 & 35,800 & 67,000 & 8,2 & 4,1 & 3,4 & 18,0 & 76,5 \\
\hline L3ED & 5,5 & 0,361 & 75,4 & 234,0 & 35,100 & 67,000 & 8,5 & 3,9 & 3,2 & 17,5 & 75,5 \\
\hline $\mathrm{T}$ & 5,4 & 0,260 & 107,0 & 117,0 & 39,000 & 68,400 & 9,1 & 2,8 & 4,3 & 18,7 & 76,9 \\
\hline $\mathrm{TA}$ & 5,4 & 0,300 & 382,0 & 156,0 & 39,700 & 75,100 & 10,6 & 4,0 & 5,4 & 19,4 & 77,9 \\
\hline
\end{tabular}

* CE - condutividade elétrica; pH-extraído pelo cloreto de cálcio; P-fósforo; K-Potássio; C-carbono; M0-Matéria Orgânica; Ca-Cálcio; Mg-Magnésio; H+Al - Hidrogênio + Alumínio; CTC-Capacidade de troca catiônica; V-Porcentagem de saturação de bases.

O teor de fósforo no solo foi considerado alto em relação ao recomendado por EMBRAPA e IAPAR (apud COAMO/ COODETEC, 2001). As concentrações de matéria orgânica e carbono foram altas e indicaram elevação da matéria orgânica e, como conseqüência, elevação do nível de C, $\mathrm{N}$ e P no solo (Ponte, 1992).

O nível de potássio na análise do solo, determinado pelo método de Melich, foi classificado alto, segundo COAMO/ COODETEC (2001). Com exceção do tratamento T, que apresentou teor referendado como médio pelos autores supracitados, indicando influência da fertirrigação nas características do solo se comparado ao solo antes do início da fertirrigação para esse elemento.

Os resultados obtidos mostraram que, com os efluentes das lagoas de tratamento, as fertirrigações provocaram aumento médio de $11 \%$ nos teores de matéria orgânica do solo, principalmente para o tratamento L1E e L1ED se comparados com a análise inicial do mesmo solo, embora TA mostrasse que a adubação química superou a fertirrigação para este parâmetro, em que uma das preocupações seria em relação ao $\mathrm{pH}$ do solo, entretanto, as análises das parcelas indicaram que as maiores variações chegaram a $8 \%$ para as parcelas fertirrigadas com efluentes; portanto, não se pode afirmar que houve modificações sensíveis deste parâmetro.

Os teores de cálcio e magnésio não tiveram acréscimo para o sistema de fertirrigações quando se utilizaram os efluentes.

De modo geral, percebe-se que o tratamento TA apresentou as maiores concentrações em todos os parâmetros demonstrando, possivelmente, que os nutrientes da adubação química não foram totalmente absorvidos pela cultura.

Todos os teores apresentados na Tabela 3 foram maiores que aqueles apresentados por Cereda (2001), fato este devido à taxa de aplicação da autora de $200 \mathrm{~m}^{3} \mathrm{ha}^{-1}$ e no experimento ter usado $632 \mathrm{~m}^{3} \mathrm{ha}^{-1}$.

\section{Parâmetros de crescimento}

Os resultados médios experimentais referentes à altura e diâmetro do colmo das plantas nas amostragens dos tratamentos foram avaliados pelo Teste de Tukey a nível de 5\% de significância (Tabela 3).

Observa-se, nos dados contidos na Tabela 3, que, ape- sar das diferenças significativas em 15/02/03, as mais acentuadas entre os tratamentos para as alturas de plantas ocorreram em 17/03/03, principalmente para o L1E, L1ED e TA. Nota-se, pelos dados da Tabela 1, que os tratamentos L1E, L1ED, oriundos da lagoa 1, apresentaram os maiores teores de nitrogênio porque, segundo Mendonça et al. (1999), a fase mais significativa de absorção de nutrientes ocorre entre 23 e 54 dias após a germinação, período no qual se deve fazer a fertirrigação, enfatizando-se o nitrogênio.

Constatou-se, a partir dos resultados médios para o diâmetro dos colmos das plantas de milho (Tabela 3), que os efeitos dos tratamentos foram distintos e se acentuaram no dia 08/04/03, em que tanto a altura quanto os diâmetros de colmos foram proporcionais ao crescimento da planta (Fernandes et al., 1991).

Por outro lado, plantas que receberam maior dosagem de zinco (L1E) apresentaram maior diâmetro de colmo em relação às demais. Segundo Rosolem \& Oliveira (1998), muitas vezes não se determinam diferenças de diâmetro de colmo mas as plantas de milho que recebem tratamento contendo zinco, sofrem menos acamamento na época da colheita, melhorando a translocação do nutriente para a parte aérea da planta.

Nos dados do número de folhas não se notou diferença significativa para os tratamentos. Os índices agronômicos demonstraram que, apesar das diferenças significativas encontradas na altura e no diâmetro de planta, existe possibilidade real de se utilizar a água residuária de fecularia na cultura do milho, considerando-se as pequenas diferenças absolutas entre tratamentos para altura e diâmetro de planta; a falta de diferenças significativas entre número de folhas e, principalmente, que foram avaliados os efeitos imediatos do uso de água residuária, visto que a bibliografia consultada ressalta os benefícios a médio e longo prazos desse tipo de reúso.

\section{Características químicas da planta}

A influência dos nutrientes é um dos fatores mais significativos para a qualidade do solo e posterior desenvolvimento da planta; conseqüência disto são plantas cuja produtividade 
Tabela 3. Altura e diâmetro do colmo das plantas de milho submetidas a tratamentos de fertirrigação com água residuária de fecularia (manipueira)*

\begin{tabular}{|c|c|c|c|c|c|c|c|c|}
\hline \multirow{2}{*}{$\begin{array}{c}\text { Data de } \\
\text { avaliação }\end{array}$} & \multicolumn{8}{|c|}{ Tratamentos } \\
\hline & L1E & L1ED & L2E & L2ED & L3E & L3ED & $T$ & TA \\
\hline & \multicolumn{8}{|c|}{ Altura das plantas (cm) } \\
\hline 01/02/03 & $22,75 a$ & $24,50 a$ & $20,75 a$ & $20,00 a$ & $23,50 a$ & $23,50 \mathrm{a}$ & $24,00 \mathrm{a}$ & $27,25 b$ \\
\hline CV (\%) & 14,52 & 22,23 & 9,13 & 8,17 & 10,13 & 2,45 & 3,4 & 12,12 \\
\hline 08/02/03 & $34,25 a$ & $32,50 a$ & $36,25 a b$ & $32,75 a b$ & $35,25 a b$ & $35,00 \mathrm{ab}$ & $31,50 a$ & $36,25 b$ \\
\hline CV (\%) & 3,67 & 6,41 & 8,83 & 2,92 & 9,92 & 5,71 & 3,17 & 7,92 \\
\hline $15 / 02 / 03$ & $60,25 a$ & $61,50 a$ & $62,50 \mathrm{ac}$ & $60,75 a b c$ & $62,75 \mathrm{ac}$ & $62,25 a b c$ & $59,50 \mathrm{~b}$ & $63,00 \mathrm{c}$ \\
\hline CV (\%) & 3,92 & 2,10 & 2,07 & 3,12 & 2,00 & 0,80 & 0,97 & 2,24 \\
\hline 22/02/03 & $84,75 a$ & $90,00 \mathrm{a}$ & $89,50 a$ & $84,25 a$ & $91,50 \mathrm{a}$ & $84,50 a$ & $83,25 a$ & $89,25 a$ \\
\hline CV (\%) & 4,85 & 0,91 & 5,52 & 1,14 & 6,53 & 17,75 & 2,67 & 4,61 \\
\hline 02/03/03 & $118,25 a$ & $112,50 \mathrm{a}$ & $123,75 a$ & $116,75 a$ & $120,25 a$ & $107,75 a$ & $107,50 \mathrm{a}$ & $123,25 a$ \\
\hline CV (\%) & 9,59 & 1,15 & 1,53 & 8,14 & 4,72 & 19,03 & 4,12 & 4,61 \\
\hline 08/03/03 & $129,75 a$ & $126,50 \mathrm{a}$ & $126,00 \mathrm{a}$ & $127,50 \mathrm{a}$ & $126,00 \mathrm{a}$ & $128,50 a$ & $124,50 \mathrm{a}$ & $131,00 \mathrm{a}$ \\
\hline CV (\%) & 3,47 & 1,88 & 3,37 & 1,98 & 1,71 & 2,33 & 1,67 & 1,53 \\
\hline $17 / 03 / 03$ & $161,00 \mathrm{a}$ & $147,75 a$ & $132,75 \mathrm{bc}$ & $145,75 \mathrm{cdc}$ & $136,00 \mathrm{bcd}$ & $130,75 b c$ & $147,50 \mathrm{dc}$ & $142,75 b c$ \\
\hline CV (\%) & 5,92 & 6,11 & 1,67 & 2,26 & 6,09 & 4,21 & 2,32 & 5,98 \\
\hline 24/03/03 & $177,50 \mathrm{a}$ & $143,50 \mathrm{~b}$ & $137,00 \mathrm{~b}$ & $147,00 \mathrm{~b}$ & $136,75 b$ & $130,75 b$ & $147,00 \mathrm{~b}$ & $142,75 b$ \\
\hline CV (\%) & 1,17 & 4,87 & 3,42 & 3,59 & 6,97 & 4,20 & 1,75 & 5,98 \\
\hline $02 / 04 / 03$ & $181,25 a$ & $143,50 \mathrm{~b}$ & $137,75 b$ & $149,50 \mathrm{~b}$ & $136,75 b$ & $137,75 b$ & $147,50 \mathrm{~b}$ & $146,50 \mathrm{~b}$ \\
\hline CV (\%) & 1,09 & 4,87 & 3,10 & 3,88 & 6,98 & 3,10 & 2,32 & 8,58 \\
\hline 08/04/03 & $182,25 a$ & $144,00 \mathrm{bc}$ & $141,25 b$ & $149,50 \mathrm{bcd}$ & $139,50 \mathrm{~b}$ & $150,00 \mathrm{bcd}$ & $152,25 \mathrm{~cd}$ & $160,25 d$ \\
\hline \multirow[t]{2}{*}{ CV (\%) } & 0,94 & 4,67 & 3,39 & 3,88 & 6,94 & 3,31 & 0,33 & 3,90 \\
\hline & \multicolumn{8}{|c|}{ Diâmetro do colmo (cm) } \\
\hline 01/02/03 & $0,84 a$ & $0,85 a$ & $0,88 a$ & $0,84 a$ & $0,83 a$ & $0,83 a$ & $0,88 a$ & $0,93 \mathrm{a}$ \\
\hline CV (\%) & 5,72 & 11,76 & 11,62 & 8,95 & 24,99 & 11,51 & 3,30 & 10,35 \\
\hline 08/02/03 & $1,80 \mathrm{a}$ & $1,68 a$ & $1,90 \mathrm{a}$ & $1,78 a$ & $1,93 a$ & $1,80 \mathrm{a}$ & $1,68 a$ & $1,88 \mathrm{a}$ \\
\hline CV (\%) & 12,00 & 7,51 & 14,25 & 7,09 & 26,28 & 7,86 & 8,96 & 15,92 \\
\hline $15 / 02 / 03$ & $2,23 a$ & $1,70 \mathrm{~b}$ & $2,68 c$ & $1,95 b$ & $2,50 \mathrm{ac}$ & $2,53 \mathrm{ac}$ & $2,00 \mathrm{~b}$ & $2,40 \mathrm{ac}$ \\
\hline CV (\%) & 2,25 & 8,32 & 11,16 & 2,96 & 0,0 & 1,98 & 0,0 & 7,61 \\
\hline 22/02/03 & $2,33 a$ & $1,83 b$ & $2,95 \mathrm{ac}$ & $2,78 \mathrm{~cd}$ & 2,65 acd & 2,63acd & $2,38 \mathrm{ad}$ & $3,00 \mathrm{c}$ \\
\hline CV (\%) & 5,41 & 2,74 & 5,87 & 7,43 & 9,34 & 3,62 & 10,53 & 7,70 \\
\hline 02/03/03 & $3,40 \mathrm{a}$ & $2,95 a$ & $3,25 a$ & $3,18 a$ & $3,57 a b$ & $3,18 a b$ & $3,43 a b$ & $3,23 a b c$ \\
\hline CV (\%) & 7,20 & 3,33 & 8,88 & 6,50 & 8,03 & 3,96 & 9,65 & 6,87 \\
\hline 08/03/03 & $3,68 a$ & $3,33 a$ & $3,63 a$ & $3,63 a$ & $3,68 \mathrm{a}$ & $3,53 a$ & $3,78 a b$ & $3,73 a b$ \\
\hline CV (\%) & 4,64 & 2,88 & 7,27 & 2,98 & 4,08 & 3,57 & 5,46 & 7,39 \\
\hline $17 / 03 / 03$ & $3,35 \mathrm{ac}$ & $3,00 a b$ & $3,37 \mathrm{ac}$ & $3,28 a$ & $2,70 \mathrm{~b}$ & $3,73 \mathrm{c}$ & $3,48 \mathrm{ac}$ & $3,65 \mathrm{ac}$ \\
\hline CV (\%) & 7,10 & 0,0 & 10,37 & 6,77 & 6,76 & 4,58 & 5,44 & 7,25 \\
\hline $24 / 03 / 03$ & $3,00 a b$ & $3,00 a b$ & $3,13 a b$ & $2,80 \mathrm{c}$ & $2,70 a$ & $3,35 b$ & $3,30 \mathrm{~b}$ & $3,48 b$ \\
\hline CV (\%) & 5,44 & 0,0 & 8,00 & 12,71 & 6,76 & 3,85 & 10,50 & 11,84 \\
\hline 02/04/03 & $2,88 a b c$ & $3,10 \mathrm{ac}$ & $2,38 b$ & 2,63abc & $2,70 a b c$ & $3,00 \mathrm{c}$ & $3,08 \mathrm{c}$ & $2,98 \mathrm{c}$ \\
\hline CV (\%) & 10,39 & 6,45 & 10,53 & 9,52 & 6,76 & 0,00 & 3,11 & 18,48 \\
\hline 08/04/03 & $2,68 \mathrm{ac}$ & $3,00 \mathrm{a}$ & $2,18 b c$ & $2,50 \mathrm{c}$ & $2,23 \mathrm{c}$ & $2,53 c$ & $2,85 \mathrm{ac}$ & $2,75 \mathrm{ac}$ \\
\hline CV (\%) & 7,71 & 9,87 & 10,86 & 0,0 & 9,27 & 19,80 & 3,51 & 11,75 \\
\hline
\end{tabular}

* As médias dos tratamentos seguidas de mesma letra na linha não diferenciam entre si pelo teste de Tukey ao nível de $5 \%$ de significância

final pode ser alterada se não houver equilíbrio do solo com o da planta. Os resultados médios experimentais referentes à caracterização química do tecido foliar e raiz nas amostragens dos tratamentos, após o término da fertirrigação, são apresentados na Tabela 4.

Conforme Malavolta et al. (1989), os níveis de magnésio, cálcio e ferro encontrados no tecido foliar, foram considerados adequados para a cultura do milho, embora os demais nutrientes estejam abaixo do essencial para a planta, ressaltando-se a necessidade de realização de outros estudos com doses mais elevadas do efluente, visando encontrar o nível crítico de aplicação do resíduo confirmado por Santos et al. (1975); já para os teores de magnésio, cálcio e ferro, os tratamentos não apresentaram diferença significativa a nível de 5\% de significância.

As análises dos teores de macro e micronutrientes nas folhas indicaram, de modo geral, que os teores de nitrogênio e potássio aplicados de forma diferenciada, quando comparada com a aplicação da fertirrigação, não foram afetados pelos tratamentos mas o fósforo, apesar de se encontrar abaixo do nível recomendado de acordo com EMBRAPA (1999), apresentou diferença significativa entre os tratamentos que tinham sido afetados devido, possivelmente, às condições de experimento. 
Tabela 4. Características químicas do tecido foliar e raiz das plantas de milho submetidas a tratamentos de fertirrigação com água residuária de fecularia (manipueira)*

\begin{tabular}{|c|c|c|c|c|c|c|c|c|}
\hline \multirow{2}{*}{ Nutriente } & \multicolumn{8}{|c|}{ Tratamentos } \\
\hline & L1E & L1ED & L2E & L2ED & L3E & L3ED & $T$ & TA \\
\hline & \multicolumn{8}{|c|}{ Tecido foliar } \\
\hline$P\left(g_{k g}^{-1}\right)$ & 1,23abc & $0,71 \mathrm{c}$ & $0,75 a b c$ & $0,59 \mathrm{ac}$ & $0,63 a c$ & $0,32 \mathrm{~b}$ & $0,63 c$ & $0,77 a b c$ \\
\hline CV (\%) & 52,11 & 25,09 & 30,27 & 7,95 & 23,18 & 32,70 & 21,81 & 47,31 \\
\hline$K\left(\mathrm{~g} \mathrm{~kg}^{-1}\right)$ & $13,75 a$ & $8,25 a$ & $8,50 a$ & $14,00 \mathrm{a}$ & $13,00 a$ & $8,25 a$ & $10,50 a$ & $11,50 \mathrm{a}$ \\
\hline CV (\%) & 39,56 & 43,56 & 22,53 & 25,42 & 59,25 & 24,99 & 9,52 & 11,23 \\
\hline $\mathrm{Zn}\left(\mathrm{mg} \mathrm{kg}^{-1}\right)$ & 1,071abc & 1,050abc & $0,946 a b c$ & $0,772 \mathrm{a}$ & $0,825 a b$ & $1,203 b c$ & $0,992 a b c$ & $12,88 \mathrm{c}$ \\
\hline CV (\%) & 20,59 & 17,28 & 21,25 & 45,43 & 19,08 & 23,22 & 11,46 & 6,63 \\
\hline $\mathrm{Fe}\left(\mathrm{mg} \mathrm{kg} \mathrm{kg}^{-1}\right)$ & $25,33 a$ & $21,23 a$ & $21,07 a$ & $28,68 a$ & $25,58 a$ & $23,85 a$ & $28,57 a$ & $31,81 a$ \\
\hline CV (\%) & 29,21 & 27,43 & 32,26 & 20,37 & 62,84 & 18,56 & 9,21 & 22,93 \\
\hline $\operatorname{Mg}\left(\mathrm{g} \mathrm{kg}^{-1}\right)$ & $3,930 \mathrm{a}$ & $3,64 a$ & $3,30 \mathrm{a}$ & $3,64 a$ & $3,63 a$ & $3,60 \mathrm{a}$ & $3,58 a$ & $3,51 a$ \\
\hline CV (\%) & 12,84 & 15,81 & 17,97 & 24,42 & 20,04 & 27,31 & 7,09 & 16,89 \\
\hline $\mathrm{Ca}\left(\mathrm{g} \mathrm{kg}^{-1}\right)$ & 4,33a & $4,33 a$ & $3,40 \mathrm{a}$ & $4,29 a$ & $3,59 a$ & $3,50 \mathrm{a}$ & $3,65 a$ & $4,23 a$ \\
\hline CV (\%) & 28,67 & 30,96 & 30,15 & 28,06 & 31,29 & 35,49 & 13,65 & 29,94 \\
\hline$N\left(g_{k g}^{-1}\right)$ & $14,50 \mathrm{a}$ & $12,13 a$ & $13,38 \mathrm{a}$ & $10,00 \mathrm{a}$ & 7,63a & $14,38 \mathrm{a}$ & $8,88 a$ & $9,00 \mathrm{a}$ \\
\hline \multirow[t]{2}{*}{ CV $(\%)$} & 47,86 & 7,04 & 29,34 & 31,00 & 14,54 & 36,30 & 10,82 & 9,06 \\
\hline & \multicolumn{8}{|c|}{ Raiz } \\
\hline$P\left(\mathrm{~g} \mathrm{~kg}^{-1}\right)$ & $0,94 a b$ & $0,94 a b$ & $1,03 a$ & $0,78 a b$ & $0,92 a b$ & $0,96 a b$ & $0,96 a b$ & $0,71 b$ \\
\hline CV (\%) & 16,67 & 11,94 & 5,53 & 16,12 & 18,46 & 18,18 & 14,43 & 2,42 \\
\hline$K\left(g^{k g}{ }^{-1}\right)$ & $10,00 \mathrm{a}$ & $6,75 a$ & $8,00 a$ & $10,00 a$ & $10,00 a$ & $9,00 \mathrm{a}$ & $9,50 \mathrm{a}$ & $10,50 a$ \\
\hline CV (\%) & 14,14 & 22,22 & 10,20 & 42,43 & 31,62 & 25,66 & 20,16 & 19,83 \\
\hline $\mathrm{Zn}\left(\mathrm{mg} \mathrm{kg}^{-1}\right)$ & $24,25 a b c$ & $27,25 \mathrm{ac}$ & $30,25 \mathrm{ac}$ & $14,00 \mathrm{~b}$ & $21,50 a b c$ & $22,25 a b c$ & $24,25 a b c$ & $25,00 a$ \\
\hline CV (\%) & 20,25 & 19,50 & 18,50 & 17,50 & 16,36 & 15,35 & 17,80 & 16,95 \\
\hline $\operatorname{Mn}\left(\mathrm{mg} \mathrm{kg}^{-1}\right)$ & $18,400 \mathrm{a}$ & $16,438 a$ & $22,812 a$ & $14,825 a$ & $17,225 a$ & $20,775 a$ & $19,325 a$ & $17,863 a$ \\
\hline CV (\%) & 24,82 & 29,13 & 18,15 & 29,04 & 23,31 & 47,89 & 6,99 & 13,92 \\
\hline$S\left(g^{k g}{ }^{-1}\right)$ & $4,95 a$ & $5,56 a$ & $5,85 a$ & $4,28 a$ & $4,50 a$ & $4,48 a$ & $4,45 a$ & $5,88 a$ \\
\hline CV (\%) & 33,01 & 19,84 & 22,08 & 55,23 & 28,62 & 23,39 & 18,40 & 12,61 \\
\hline $\mathrm{Fe}\left(\mathrm{mg} \mathrm{kg}^{-1}\right)$ & $16,66 a$ & $16,91 \mathrm{a}$ & $17,10 \mathrm{a}$ & $16,06 a$ & $16,35 a$ & $16,56 a$ & $16,57 \mathrm{a}$ & $16,81 a$ \\
\hline CV (\%) & 3,06 & 1,88 & 1,52 & 7,18 & 4,44 & 2,39 & 2,22 & 1,31 \\
\hline $\operatorname{Mg}\left(\mathrm{g} \mathrm{kg}^{-1}\right)$ & $0,78 a$ & $0,78 a$ & $0,88 a$ & $0,49 a$ & $0,46 a$ & $0,69 a$ & $0,64 a$ & $1,35 b$ \\
\hline CV (\%) & 8,32 & 17,07 & 13,60 & 49,11 & 23,98 & 13,76 & 20,63 & 14,50 \\
\hline$N\left(g_{k g}^{-1}\right)$ & $9,87 \mathrm{a}$ & $9,77 \mathrm{a}$ & $12,59 a$ & $9,54 a$ & $7,95 a$ & $11,43 a$ & $10,06 a$ & $11,22 \mathrm{a}$ \\
\hline CV (\%) & 18,04 & 17,16 & 33,64 & 25,36 & 16,99 & 14,25 & 14,86 & 13,82 \\
\hline
\end{tabular}

* As médias dos tratamentos seguidas de mesma letra na linha não diferenciam entre si pelo teste de Tukey a nível de $5 \%$ de significância

Constatou-se efeito significativo do tratamento no teor de zinco, no comprimento da raiz e na planta, como um todo. Em média, a aplicação do efluente contendo zinco na superfície dos vasos levou à maior absorção do nutriente pela planta, como resultado de maior quantidade acumulada nas raízes, observando-se que a maior parte do zinco se acumulou na raiz, sendo translocado para a parte aérea da planta, evitando níveis tóxicos na parte aérea das plantas e correspondendo à literatura citada por Rosolem \& Oliveira (1998). Muitos estudos com arroz, cevada e trigo, apresentaram evidências de que plantas tolerantes a alumínio indicaram teores mais altos de fósforo, cálcio, magnésio e potássio; entretanto, esta informação não significa que tais plantas sejam efetivamente mais eficientes na absorção e utilização de fósforo (Furlani \& Furlani, 1991) porém pode ocorrer que maiores teores de fósforo e de outros nutrientes encontrados nos tecidos, sejam devidos ao maior aprofundamento e crescimento do sistema radicular tolerante ao alumínio que explorou, assim, maior volume de solo; há, sim, possibilidade deste fato ter ocorrido com os tratamentos L1E, L1ED, L2ED, L3E, L3ED e T, no experimento.
Nota-se, nos resultados encontrados nas Tabelas 3 e 4, que apenas os teores de fósforo e zinco apresentaram diferenças significativas entre os tratamentos, demonstrando o potencial de uso da manipueira tratada na irrigação da cultura do milho.

\section{CONCLUSÕES}

1. De modo geral, a irrigação com água residuária, tratada por sistema de lagoas, proporcionou aumento em todos os parâmetros químicos do solo, proporcional aos respectivos tratamentos na seguinte ordem: L1E, L1ED, L2E, L2ED, L3E, L3ED e T, exceto para o tratamento TA, que também apresentou altos teores dos elementos químicos avaliados.

2. A partir do $56^{\circ}$ dia após o plantio (17/03/03) observaram-se diferenças significativas mais acentuadas para altura de plantas proporcionadas pelos tratamentos; ao final do experimento (08/04/03) as maiores alturas de plantas foram obtidas para os tratamentos, na seguinte ordem: L1E, TA, T que, estatisticamente, diferiram entre si; seguidos de L1ED, 
L2ED e L3ED que, estatisticamente, foram semelhantes entre si; e de L2E e L3E que, estatisticamente, também foram iguais entre si todos a nível de 5\% de significância.

3. O número de folhas não apresentou diferenças significativas entre os tratamentos avaliados.

4. Apenas os teores de fósforo e zinco apresentaram diferenças significativas a nível de 5\%, entre os tratamentos nas análises químicas do tecido foliar e das raízes da cultura do milho.

\section{LITERATURA CITADA}

APHA - American Public Health Association. Standard methods for the examination of water and wastewater. 20.ed. New York: APHA, AWWA, WPCR, 1998. 1325p.

Cereda, M. P. Manejo, uso e tratamento de subprodutos da industrialização da mandioca. Série culturas de tuberosas amiláceas latinoamericanas. São Paulo: Fundação Cargill, 2001. 340p.

COAMO/COODETEC - Agroindustrial Cooperativa - Cooperativa Central de Pesquisa Agrícola. Fertilidade do solo e nutrição de plantas. 2.ed. Cascavel: COAMO, 2001. 93p.

Dourado Neto; Francelli. L. A. Produção de milho. Guaíba: Guaíba Agropecuária, 2000. 360p.

EMBRAPA - Empresa Brasileira de Pesquisa Agropecuária. Manual de métodos de análises do solo. 2.ed. Rio de Janeiro: EMBRAPA. 1997. 212p.

EMBRAPA - Empresa Brasileira de Pesquisa Agropecuária. Manual de análises químicas de solos, plantas e fertilizantes. Silva, F. C. da (org.). Brasília: Embrapa Comunicação para Transferência de Tecnologia. 1999. 370p.

Fernandes, V. L. B.; Nunes, L. A. P.; Filho, M. M.; Sousa, V. L.; Fernandes, M. B. Absorção e utilização de nitrogênio em planta de sorgo cultivado em solução nutritiva. Ciência Agronômica, Fortaleza, n.22, p.89-97, 1991.

Fioretto, R. A. Uso direto da manipueira em fertirrigação. In: Cereda, M. P. Industrialização da mandioca no Brasil. São Paulo: Paulicéia, 1994. p.51-80.

Furlani, P. R.; Furlani, A. M. C. Tolerância ao alumínio e eficiência do fósforo em milho e arroz: características independentes. Bragantia, Campinas, v.2, n.50, p.331-340, 1991.
Malavolta, E.; Vitti, G. C.; Oliveira, S. A. Avaliação do estado nutricional das plantas: Princípios e aplicações. Piracicaba: Potafós, 1989. 201p.

Mendonça, F. C.; Medeiros, R. D.; Botrel, T. A.; Frizzone, J. A. Adubação nitrogenada do milho em um sistema de irrigação por aspersão em linha. Scientia Agrícola, Piracicaba, v.56, n.4, p.1-50, 1999.

Mengel, K. E. A.; Kirkly. E. A. Principles of plant nutrition. Berne: International Potash Institute, 1978. 175p.

Nunes, R. P.; Pitombeira, J. B.; Paula Neto, H. M.; Nunes, F. F. P. Produtividade do milho (Zea mays L.) irrigado em diferentes densidades populacionais e épocas de plantio. Ciência Agronômica, Fortaleza, n.23, p.139-145, 1992.

Pereira, J. P. Utilização da rama e resíduos industriais da mandioca na alimentação animal. Informe Agropecuário, Belo Horizonte, v.13, n.145, p.28-41, 1987.

Ponte, J. J. Histórico das pesquisas sobre a utilização da manipueira (extrato líquido das raízes de mandioca) como defensivo agrícola. Fitopatologia Venezuelana, Maracay, v.5, n.1, p.2-5, 1992.

Rosolem, C. A.; Oliveira, R. F.; Absorção de zinco pelo milho em função do modo de aplicação e fontes do nutriente. Científica, São Paulo: n. 26, p.83-93, 1998.

Santos, H. L.; Bahia Filho, A. F. C.; Bahia, F.; Magnavaca, R.; Silva, J.; Murad, A. M.; Pacheco, E. B. Ensaios de adubação com nitrogênio, fósforo e potássio na cultura do milho em Minas Gerais. Pesquisa Agropecuária Brasileira, Brasília, v.10, p.47-51, 1975.

SEAB/DERAL - Secretaria da Agricultura e do Abastecimento/ Departamento de Economia Rural. Boletim do milho. Curitiba: SEAB/DERAL, 2003. 205p.

Silva, F. F. Impacto da aplicação de efluente de fecularia de mandioca em solo e na cultura do sorgo (Sorghum bicolor). Maringá: UEM, 2003. 69p. Dissertação Mestrado

Tiese-Nhausen, I. M. V. O feno e a silagem da rama de mandioca na alimentação de ruminantes. Informe Agropecuário, Belo Horizonte, v.13, n.145, p.42-47, 1987.

Vieites, R. L.; Brinholi, O. Utilização da manipueira como fonte alternativa à adubação mineral na cultura da mandioca. Revista Brasileira de Mandioca, Cruz das Almas, v.13, n.1, p.61-66, 1994. 